\title{
MÉTODOS DE APOIO AO DIAGNÓSTICO DE LESÕES MUSCULARES
}

\author{
BANDEIRA, Fábio \\ Mestre pelo Programa de Pós-Graduação em Engenharia Biomédica, da Universidade \\ Tecnológica Federal do Paraná (UTFPR). E-mail: bandeirafabio@gmail.com \\ NEVES, Eduardo Borba \\ Doutor em Engenharia Biomédica pela Universidade Federal do Rio de Janeiro (UFRJ), \\ Doutor em Saúde Pública e Meio Ambiente pela Escola Nacional de Saúde Pública \\ (FIOCRUZ), Docente do Programa de Pós-Graduação em Engenharia Biomédica da \\ Universidade Tecnológica Federal do Paraná (UTFPR). E-mail:borbaneves @ hotmail.com \\ BARROSO, Guilherme Campos
}

Médico Ortopedista e Traumatologista pelo Hospital Novo Mundo de Fraturas; Médico do Curitiba Rugby Clube - Curitiba, PR, Brasil

NOHAMA, Percy

Doutor em Engenharia Elétrica, Mestre em Engenharia Elétrica, Docente do Programa de Pós-Graduação em Engenharia Biomédica da Universidade Tecnológica Federal do Paraná (UTFPR). E-mail:percy.nohama@gmail.com

\begin{abstract}
RESUMO
As lesões musculares são comuns em atletas e indivíduos fisicamente ativos, e causam transtornos e gastos pessoais e institucionais. O tratamento depende do diagnóstico e da monitorização do estado da lesão. Por isso, o diagnóstico é uma etapa fundamental na recuperação das lesões musculares. Neste artigo, são descritos os principais métodos diagnósticos para lesões musculares, divididos em métodos de diagnóstico por imagens e por marcadores bioquímicos. Estes últimos baseiam-se na análise de concentrações de enzimas plasmáticas, como a creatina quinase, lactato desidrogenase, aspartato aminotransferase, miosina, troponina I e interleucina, para indiretamente, diagnosticar danos estruturais no músculo esquelético. Já os exames por imagem, tais como a ultrassonografia, a tomografia computadorizada, a ressonância nuclear magnética e a termografia podem produzir desde um minucioso detalhamento anatômico das partes do corpo sob análise até aspectos relacionados a sua funcionalidade. O conhecimento dos métodos instrumentaliza a decisão dos profissionais de saúde sobre o método que eles vão solicitar ou indicar em cada situação defrontada na prática clínica.
\end{abstract}

PALAVRAS-CHAVE:Doenças Musculares, Diagnóstico, Diagnóstico por Imagem, Marcadores Biológicos.

\section{METHODS FOR SUPPORT THE MUSCLE INJURY DIAGNOSIS}

\begin{abstract}
Muscle injuries are common in athletes and physically active individuals, causing inconvenience and expenses both to the individual and to the team. Choosing an appropriate treatment depends on the medical diagnostic and on the close monitoring of the injury. Therefore, the diagnostic is a critical step on the recovery of muscle injuries. In this article, we describe the main diagnostic methods for muscle injuries, here divided in two
\end{abstract}


groups, imaging diagnostics and Biomarkers. The latter is based on the plasma analysis of enzymes concentrations which indirectly diagnose structural damage in skeletal muscle. The diagnostic imaging methods such as ultrasound, computed tomography, magnetic resonance imaging and thermography can produce detailed anatomical visualization of specific body regions and related aspects of its functionality. The knowledge of the methods described in this paper can assist health professionals on choosing the most appropriate method they for each specific case.

KEYWORDS:Doenças Musculares, Diagnóstico, Diagnóstico por Imagem, Marcadores Biológicos.

\section{MÉTODOS DE APOIO AO DIAGNÓSTICO DE LESÕES MUSCULARES}

\section{INTRODUÇÃO}

Lesões musculares são muito comuns e costumam afastar os atletas da prática esportiva (PETERSON; RENSTRÖM, 2002), o que é obviamente um transtorno e gera gastos aos clubes. Esportes como futebol e rugby caracterizam-se por serem atividades intermitentes de longa duração (CUNNIFFE et al., 2010; GABBETT, 2003; GARRETT JR.; KIRKENDALL, 2003; JOUGLA; MICALLEF; MOTTET, 2010; SARGENTIM, 2010), com intensidade de exercício variável e ações diversas (chutes, lançamentos de bola, tackles, saltos, giros, fortes contrações para manutenção do equilíbrio) (ALVES; SOARES; LIEBANO, 2008; BAUDUER et al., 2011; GABBETT, 2003; STOLEN et al., 2005). Esses esportes envolvem, portanto, enorme quantidade de ações de contração excêntrica (CUNNIFFE et al., 2010; MOUGIOS, 2007), que causam alterações morfológicas nas fibras musculares (ESTON; BYRNE; TWIST, 2003; ISPIRLIDIS et al., 2008).

Existem diversos métodos para análise e diagnóstico de lesões musculares causadas pela atividade física (FOSCHINI; PRESTES; CHARRO, 2007): medição da atividade de enzimas plasmáticas (por exemplo: creatina quinase, lactato desidrogenase, troponina I e mioglobina), registro da ação voluntária máxima, aquisição de respostas subjetivas de dor por meio de escala de percepção, ressonância magnética, ultrassonografia, tomografia, eletromiografia de superfície, termografia e amostra do músculo, são alguns dos métodos utilizados (BANDEIRA et al., 2012; DUFFIELD et al., 2012; FERNANDES; PEDRINELLI; HERNANDEZ, 2011; FOSCHINI et al., 2007; SBRICCOLI et al., 2001). Neste sentido, o presente estudo teve por objetivo descrever os principais métodos de apoio ao diagnóstico de lesões musculares. Para uma melhor organização das informações, os métodos foram divididos em: diagnóstico por imagem e diagnóstico por marcadores bioquímicos.

\section{DIAGNÓSTICO POR IMAGEM}

Exames por imagem podem ser úteis para auxiliar no diagnóstico de lesões com maior precisão (FERNANDES et al., 2011; YENG; KAZIYAMA; TEIXEIRA, 2003). A seguir, descrevem-se alguns dos exames por imagens mais utilizados. 


\section{Ultrassom}

A ultrassonografia (ultrassom ou ecossonografia) (BONTRAGER, 2003) é uma técnica empregada para a obtenção de imagens, que utiliza ondas sonoras de alta frequência (BONTRAGER, 2003; BONTRAGER; LAMPIGNANO, 2010). Trata-se de um procedimento não-invasivo, que envolve a utilização de radiação não-ionizante e que proporciona avaliação diagnóstica pelas reflexões dessas ondas de alta frequência, gerando informações sobre todas as partes do corpo (STIMAC, 1994). O ultrassom baseia-se nos fenômenos de refração e reflexão das ondas sonoras nas interfaces dos meios com índices de refração acústica distintos (WEBB, 1988).

As ondas ultrassônicas são produzidas e direcionadas para o interior do corpo até atingirem uma barreira tissular que irá refleti-las para o transdutor (BONTRAGER, 2003; SUTTON, 1996). As ondas produzidas atingem uma velocidade de cerca $1500 \mathrm{~m} / \mathrm{s}$ (SUTTON, 1996) e quando refletidas, são denominadas ecos (BONTRAGER, 2003).

O transdutor é um cristal vibratório acionado eletricamente que tem a função de converter energia elétrica em energia ultrassônica (BONTRAGER, 2003; BONTRAGER; LAMPIGNANO, 2010; BRANT; HELMS, 2008; SUTTON, 1996; WEBB, 1988). Provavelmente, o transdutor é o componente mais importante no sistema de imagem de ultrassom (WEBB, 1988). O transdutor tanto envia quanto recebe as ondas de eco, agindo tanto como transmissor quanto receptor, convertendo as ondas em tensões elétricas novamente (BONTRAGER, 2003; BONTRAGER; LAMPIGNANO, 2010; SUTTON, 1996; TAN et al., 2009). Estas ondas de alta frequência (2 a $20 \mathrm{MHz}$ ) são utilizadas para gerar as imagens (BONTRAGER, 2003; MITTELSTAEDT, 2000; PRANDO; MOREIRA, 2007; STIMAC, 1994). Tal frequência não é transmissível em ar ou gás, apenas em sólidos e líquidos (BONTRAGER, 2003; BONTRAGER; LAMPIGNANO, 2010).

As imagens são produzidas pela oscilação longitudinal contra a superfície do tecido (STIMAC, 1994). A intensidade das ondas pode ser alterada visando otimizar a penetração (STIMAC, 1994). Essas ondas são parcialmente refletidas pelo plano tecidual profundo, sendo parte delas recebidas pelo transdutor (STIMAC, 1994). Transdutores de 7,5 a 10 $\mathrm{MHz}$ alcançam profundidades de 3 a $4 \mathrm{~cm}$ e são utilizados na avaliação de tecidos superficiais, enquanto no exame de músculos mais profundos são utilizados transdutores de 5 a 3,5 MHz, os quais realizam varreduras de 7 a $8 \mathrm{~cm}$, podendo ser utilizados, tanto no caso do sujeito possuir uma maior massa muscular ou tecido subcutâneo gorduroso excessivo, quanto para avaliar uma lesão ou um grande segmento anatômico (MITTELSTAEDT, 2000). Quanto maior a frequência nominal do transdutor, menor a profundidade de penetração (BONTRAGER; LAMPIGNANO, 2010; BRANT; HELMS, 2008; MITTELSTAEDT, 2000) e melhor é a resolução espacial da imagem (BONTRAGER, 2003; BONTRAGER; LAMPIGNANO, 2010; BRANT; HELMS, 2008). O transdutor utilizado determina o formato e aspecto da imagem resultante (BRANT; HELMS, 2008). Para localizar lesões tridimensionais ou calcular volume é necessária a combinação das varreduras longitudinal e transversal (MITTELSTAEDT, 2000).

Recentemente, iniciou-se a obtenção de imagens musculoesqueléticas para diagnóstico, que podem ser utilizadas como complemento à ressonância magnética ou triagem para realização desta e vem se tornando uma ferramenta suplementar valiosa em medicina esportiva (BONTRAGER, 2003; BONTRAGER; LAMPIGNANO, 2010). A 
ultrassonografia de alta resolução é ideal para avaliação de tecidos intersticiais moles, como músculos e tendões (MITTELSTAEDT, 2000). Exames de imagem ultrassônica fornecem informações para verificação e determinação da lesão com grande precisão (FERNANDES et al., 2011). Por ser um método relativamente barato, a ultrassonografia tem sido eleita como o principal método para o diagnóstico clínico de lesões musculares (JARVINEN et al., 2007).

Dentre as vantagens dos exames ultrassonográficos, quando comparados às outras técnicas de obtenção de imagens, pode-se citar: são mais baratos que os exames de tomografia computadorizada e ressonância magnética (FERNANDES et al., 2011; MITTELSTAEDT, 2000; STIMAC, 1994); possibilitam verificar e caracterizar lesões de difícil diagnóstico clínico, como aquelas dentro do ventre muscular (FERNANDES et al., 2011; JARVINEN et al., 2007); quando utilizados aparelhos de tempo real, o exame é rápido e completo, não deixando ponto cego entre os cortes (MITTELSTAEDT, 2000); a obtenção de imagens por ultrassonografia é inócua, indolor e não-invasiva (BONTRAGER, 2003); possibilitam avaliação dinâmica dos tecidos moles (BONTRAGER, 2003).

Dentre as desvantagens da utilização desta técnica, citam-se: a obtenção das imagens é fortemente dependente do examinador (BONTRAGER; LAMPIGNANO, 2010; FERNANDES et al., 2011; JARVINEN et al., 2007), pois é ele quem interpreta as imagens (BONTRAGER, 2003); estruturas ósseas e preenchidas por ar são barreiras para as ondas de alta frequência, dificultando a visualização de áreas anatômicas circundadas por osso (BONTRAGER, 2003; BRANT; HELMS, 2008).

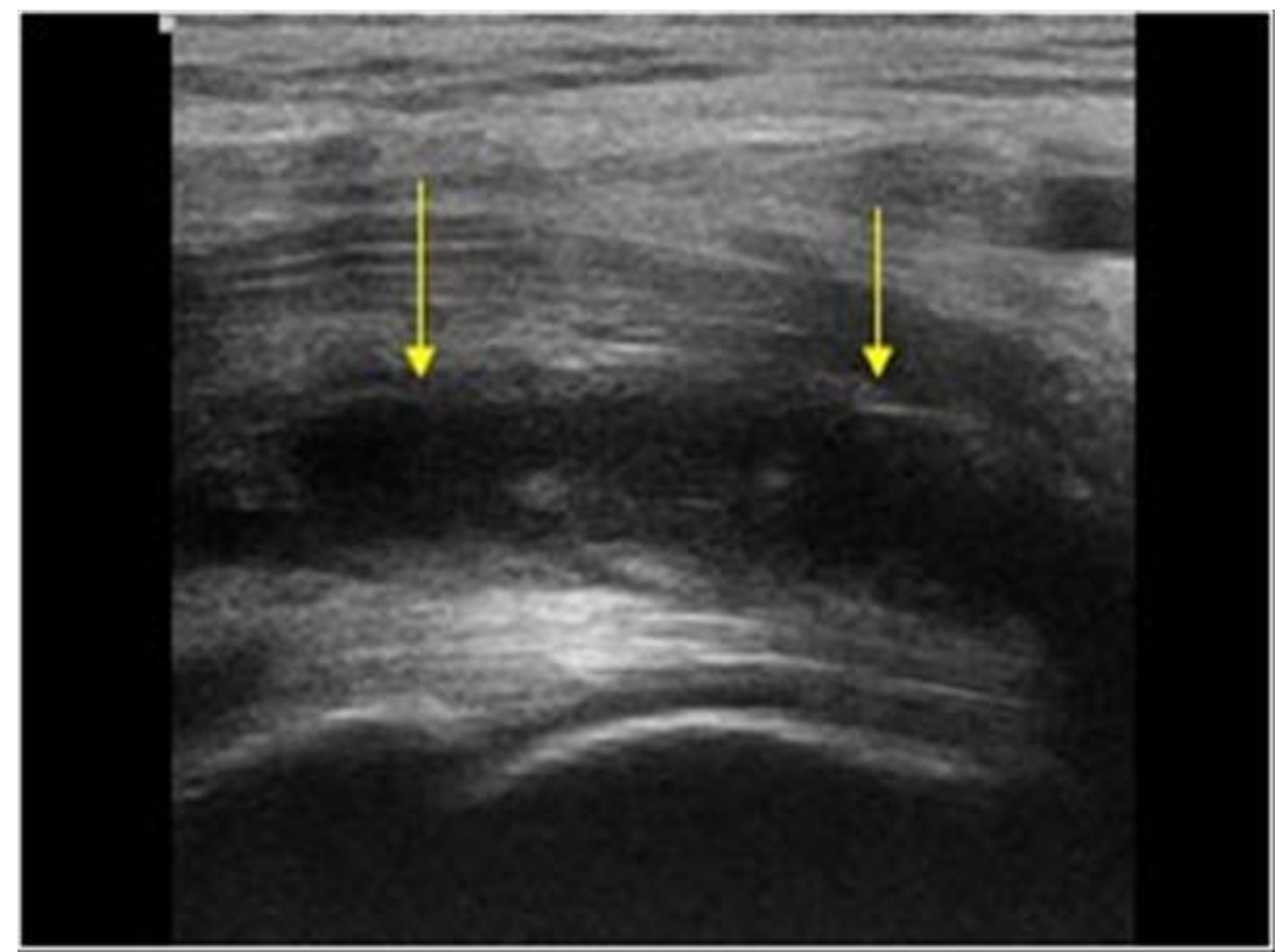

Figura 1 - Imagem ilustrativa do método de ultrassonografia, demonstrando uma lesão do músculo vasto medial.

Fonte: acervo do Autor 


\section{Tomografia Computadorizada (TC)}

A tomografia computadorizada produz um minucioso detalhamento anatômico de todas as partes do corpo (STIMAC, 1994). É um método de produção de imagens por meio dos raios-X que incidem sobre detectores que convertem fótons em cintilações. As cintilações produzidas são quantificadas e gravadas e as informações são transmitidas a um computador (SUTTON, 1996), que emprega uma técnica de reconstrução matemática para produzir a imagem (STIMAC, 1994). A TC parte do princípio que os filmes convencionais de raios-X fornecem apenas uma pequena proporção dos dados disponíveis e que, por meio de escaneamento multidirecional, múltiplos dados decorrentes dos tecidos que estiverem no caminho dos feixes de raios-X uma maior quantidade de dados será coletada (SUTTON, 1996).

Dentre as vantagens, incluem-se: ótima resolução espacial e, portanto, anatômica; elevada precisão e especificidade na definição da lesão (FERNANDES et al., 2011); e alta sensibilidade para caracterizar lesões de difícil diagnóstico clínico, como lesões dentro do ventre muscular (FERNANDES et al., 2011; JARVINEN et al., 2007).

Dentre as desvantagens, encontram-se: utilização de radiação ionizante (SCHAAP et al., 2008); alto custo do exame (LOPES et al., 1993); fornecimento de detalhes estritamente anatômicos, não sendo capaz de demonstrar alterações fisiológicas e metabólicas (ITAKURA, 2012).

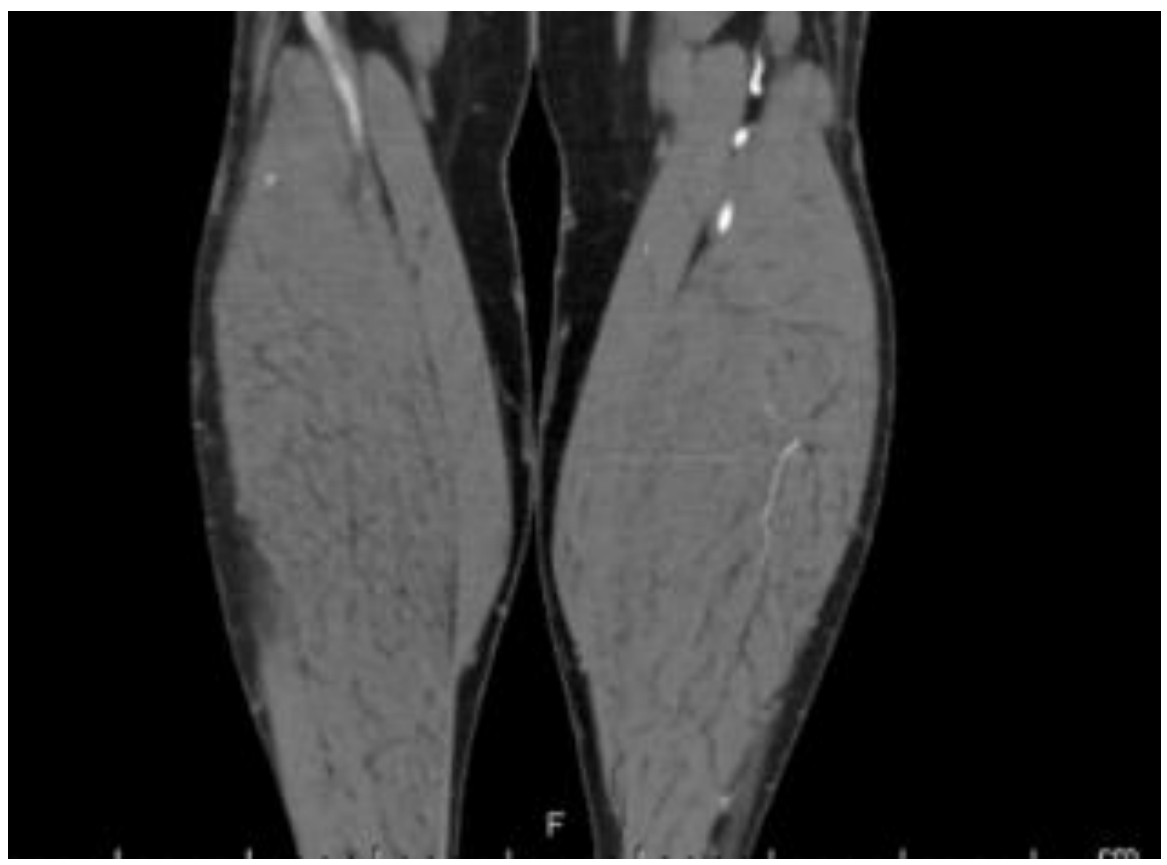

Figura 2- Imagem ilustrativa do método de tomografia computadorizada. Grupos musculares íntegros, sem lesão aparente.

Fonte: acervo do Autor

\section{Ressonância Nuclear Magnética (RNM)}

O tecido biológico apresenta, em nível microscópico (átomos ou núcleos), propriedades magnéticas com intensidade variável (DOYON et al., 2000). A ressonância é um fenômeno que ocorre quando há exposição de algum objeto, neste caso, o núcleo do hidrogênio, a uma perturbação oscilatória com frequência próxima a sua própria frequência natural de 
oscilação (WESTBROOK; KAUT, 2000). Haverá transferência de energia da onda de radiofrequência para o núcleo exposto caso seja aplicada exatamente na frequência do núcleo (DOYON et al., 2000; WESTBROOK; KAUT, 2000).

Este método baseia-se no fato de que alguns núcleos, tais como os prótons de hidrogênio, comportam-se como minúsculos magnetos que, quando submetidos a um campo magnético externo forte, alinham-se sob esse novo eixo magnético (SUTTON, 1996; WESTBROOK; KAUT, 2000).

O núcleo do átomo de hidrogênio é atualmente utilizado nas imagens em ressonância magnética (DOYON et al., 2000), e na maioria das imagens obtidas em seres humanos (LUFKIN, 1999). O núcleo do átomo de hidrogênio contém apenas um próton, e é o núcleo ativo na RNM por ser abundante no corpo humano e por seu único próton proporcionar um momento magnético grande (LUFKIN, 1999; WESTBROOK; KAUT, 2000). A obtenção de uma imagem matematicamente reconstruída ocorre com a utilização de campos magnéticos e ondas de rádio (BONTRAGER, 2003; SUTTON, 1996). A RNM utiliza, portanto, pulsos de ondas de rádio necessários para detectar os prótons magnetizados (SUTTON, 1996). A interação entre os núcleos e os campos magnéticos aplicados externamente, resultam em sinais que, por meio da representação das intensidades dos sinais eletromagnéticos de núcleos de hidrogênio, constituirão imagens em duas ou três dimensões (STIMAC, 1994).

Uma forma de medir o dano estrutural muscular induzido pela atividade física por meio de método direto é a captura de imagens empregando a técnica de ressonância magnética (FOSCHINI et al., 2007). A RNM oferece excelente resolução espacial, bem como elevado contraste, ambas qualidades necessárias para a imagem musculoesquelética (STIMAC, 1994). Esta técnica pode ser aplicada para obter imagens de massas de tecido mole (STIMAC, 1994). A RNM pode confirmar (ou excluir) a existência de lesões musculares fornecendo detalhada caracterização anatômica das mesmas (JARVINEN et al., 2007).

Dentre as vantagens da RNM, apontam-se: não utilização de radiação ionizante, livrando de qualquer perigo biológico aparente (STIMAC, 1994; SUTTON, 1996); menor dependência do operador se comparada à ultrassonografia (MITTELSTAEDT, 2000); excelente discriminação dos tecidos moles (WESTBROOK; KAUT, 2000); verificação e caracterização de lesões de difícil diagnóstico clínico, como aquelas dentro do ventre muscular (FERNANDES et al., 2011; JARVINEN et al., 2007).

Dentre as desvantagens, indicam-se: alto custo dos aparelhos (SUTTON, 1996); não pode ser aplicada a pessoas que fazem uso de grampos metálicos, implantes, válvulas cardíacas, clipes vasculares, entre outros (DOYON et al., 2000; SUTTON, 1996); contraindicação absoluta a usuários de marca-passo cardíaco, visto que este pode ter seu funcionamento prejudicado de forma transitória ou definitiva pelos intensos campos magnéticos gerados (DOYON et al., 2000; SUTTON, 1996); e, por fim, o alto custo do exame (LOPES et al., 1993). 


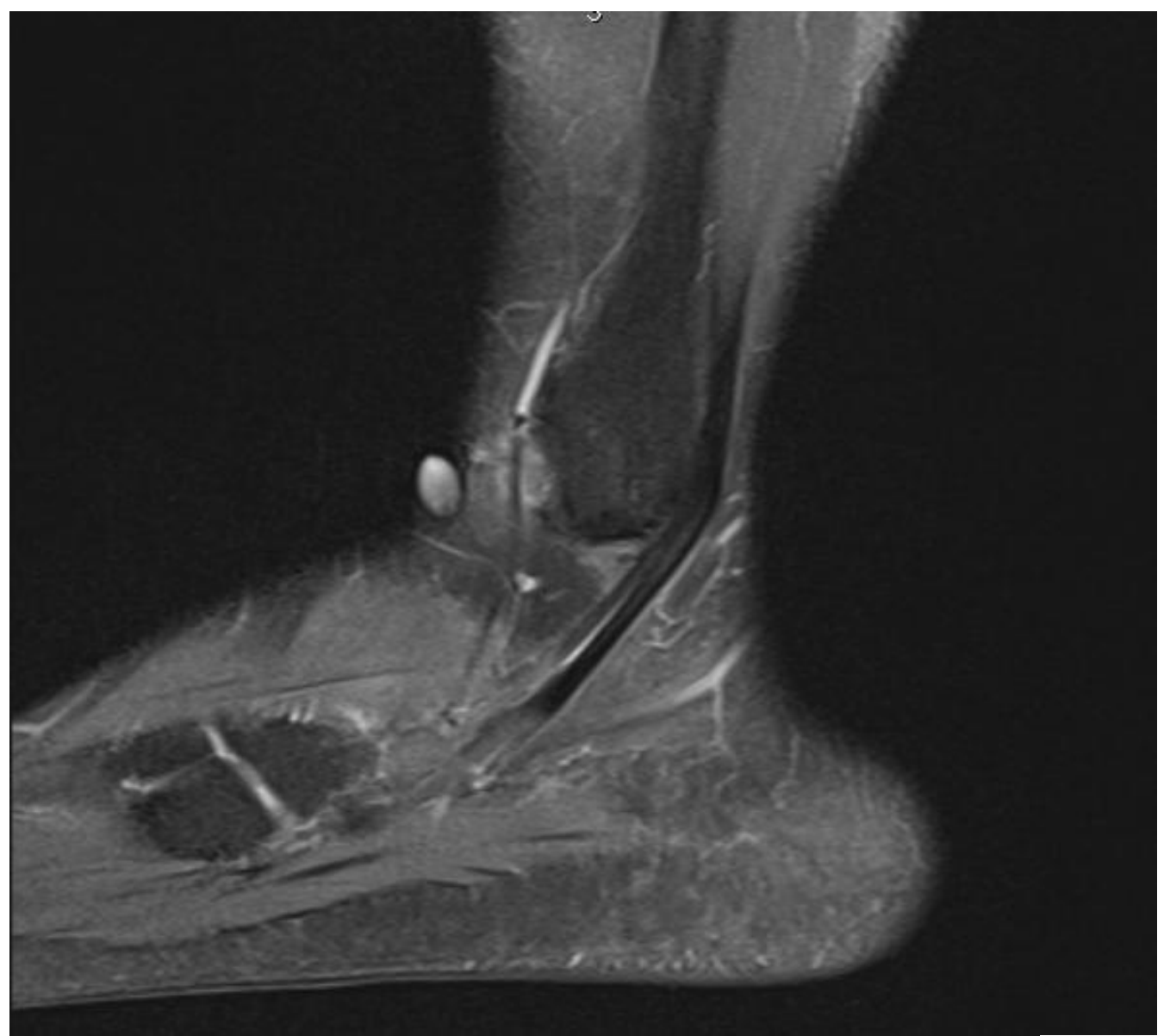

Figura 3 - Imagem ilustrativa do método de RNM demonstrando uma tendinopatia dos tendões fibulares.

Fonte: acervo do Autor

\section{Termografia}

Qualquer corpo com temperatura acima de $-273{ }^{\circ} \mathrm{C}$ emite radiação eletromagnética, a qual é conhecida por radiação infravermelha ou radiação térmica, proporcional à sua temperatura (BRIOSCHI; YENG; PASTOR; COLMAN; et al., 2007; LAHIRI et al., 2012). A radiação infravermelha é invisível a olho nu e indica o grau de agitação molecular (BRIOSCHI; YENG; PASTOR; COLMAN; et al., 2007). A imagem térmica é dependente da emissão de radiação da superfície da pele e com o auxílio de uma câmera especial, consegue-se efetuar o mapeamento térmico preciso do corpo humano, por meio da conversão da energia térmica emitida pelo corpo em sinais elétricos, que são digitalizados e apresentados em forma de imagem (ITAKURA, 2012; WEBB, 1988). A técnica consiste em detectar a radiação infravermelha emitida pelo corpo e correlacioná-la, com a distribuição de temperatura de um determinado corpo (HILDEBRANDT et al., 2012).

A termografia pode ser utilizada para investigar uma ampla variedade de condições clínicas (WEBB, 1988) e possui uma elevada especificidade diagnóstica (BERZ; SAUER, 2007). Dentre elas, estudos metabólicos, avaliações de condições inflamatórias e avaliação de dores e traumas (BRIOSCHI; YENG; PASTOR; TEIXEIRA, 2007; WEBB, 1988). É um método capaz de localizar e quantificar objetivamente reações inflamatórias do sistema musculoesquelético (BRIOSCHI; YENG; PASTOR; TEIXEIRA, 2007). 
Este método apresenta vantagens como: isenção de radiação ionizante; inocuidade; baixo custo; ser indolor (BRIOSCHI; YENG; TEIXEIRA, 2007; CARVALHO et al., 2012); inexistência de contato físico (CARVALHO et al., 2012); não-invasividade (JONES; PLASSMANN, 2002; TAN et al., 2009); não-intrusividade (TAN et al., 2009); capacidade de disponibilizar as temperaturas de uma superfície em imagens de tempo real (TAN et al., 2009); possibilidade de localizar a lesão e demonstrar mudanças metabólicas e fisiológicas em um exame funcional (ITAKURA, 2012; JONES; PLASSMANN, 2002); portabilidade do equipamento (ITAKURA, 2012).

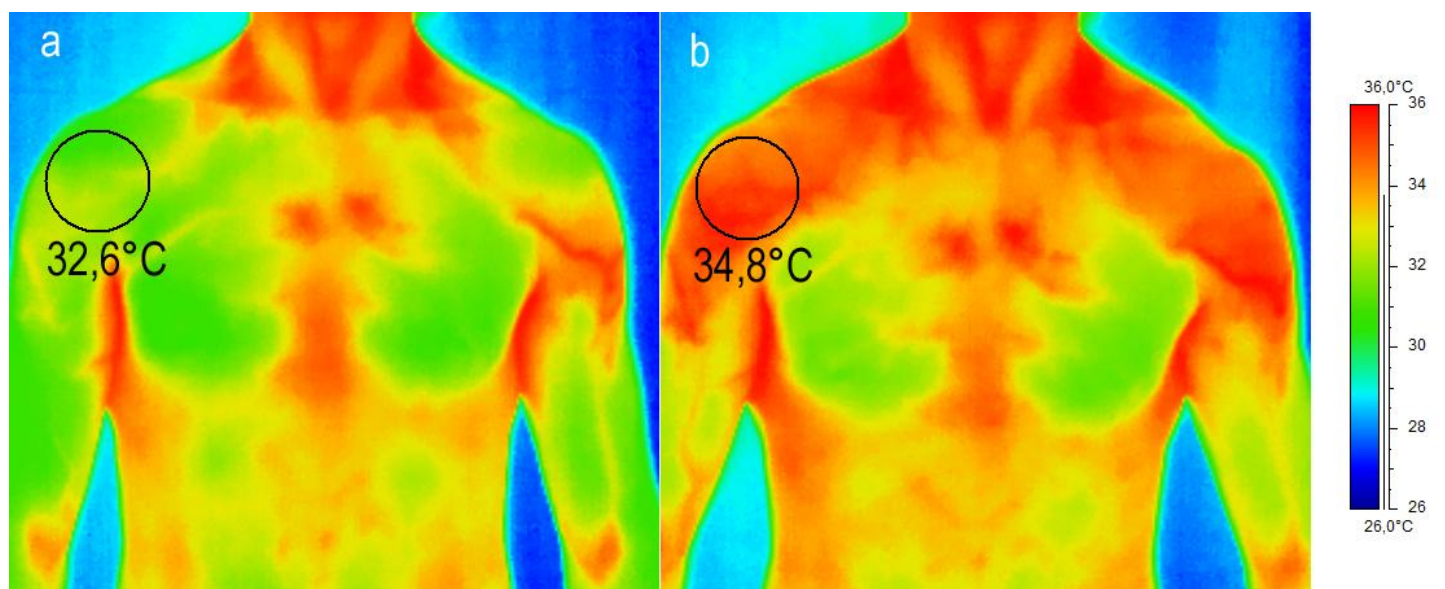

Figura 4 - imagem termográfica evidenciando lesão muscular no músculo deltóide direito em momento de (a) pré-lesão e (b) pós-lesão Fonte: acervo do Autor

\section{DIAGNÓSTICO POR MARCADORES BIOQUÍMICOS}

Grande parte das reações químicas ocorridas nos organismos vivos são catalisadas pelas enzimas (MOURA et al., 2008). Uma lesão sofrida por qualquer tecido leva as enzimas intracelulares à corrente circulatória (MOURA et al., 2008). A análise de concentrações de enzimas plasmáticas, como a creatina quinase, lactato desidrogenase, aspartato aminotransferase, miosina, troponina I e interleucina, são métodos indiretos de análise de dano estrutural causado ao músculo esquelético (DUFFIELD et al., 2012; FOSCHINI et al., 2007; VAN DE VYVER; MYBURGH, 2012). A concentração sérica dessas enzimas determina o estado funcional do tecido muscular e varia tanto em condições patológicas quanto fisiológicas (HAMMOUDA et al., 2012). Tais métodos diagnósticos são os mais utilizados por revelarem-se de baixo custo e de fácil coleta quando comparado aos métodos diretos (FOSCHINI et al., 2007).

\section{Creatina Quinase (CK)}

A creatina quinase, ou creatinofosfoquinase foi descoberta em 1934 por K. Lohmann (LÓPEZ, 1969). É uma enzima citoplasmática e mitocondrial que catalisa reações com transferência de energia: a formação da adenosina trifosfato (ATP) e do difosfato de adenosina (ADP) com fosforilação reversível da creatina (LÓPEZ, 1969; NOGUEIRA et al., 1990; PESCE; KAPLAN, 1990). Em humanos, quatro tipos de genes diferentes codificam as cinco isoenzimas de creatina quinase (PEREIRA; JUNIOR, 2007). Tal enzima é encontrada em diversos tecidos com diferentes concentrações (PESCE; KAPLAN, 1990). É encontrada principalmente na musculatura esquelética (CAMPBELL, 
2000; FERNANDES et al., 2011; FRÉJAVILLE; KAUMOUN, 1989; LÓPEZ, 1969; MOURA et al., 1982), mas também no músculo cardíaco e tecido cerebral e em menor escala nos pulmões, rins entre outros (HENRY, 1995; MOURA et al., 1982; MOURA et al., 2008).

A CK é um dímero composto por duas cadeias polipeptídicas denominadas " $\mathrm{M}$ " e "B". Estas subunidades combinam-se possibilitando a formação de três tipos de dímeros (isoenzimas): $\mathrm{CK}_{1}$ (BB). $\mathrm{CK}_{2}$ (MB) e $\mathrm{CK}_{3}$ (MM) (LO et al., 2010; MOURA et al., 1982; NOGUEIRA et al., 1990; PESCE; KAPLAN, 1990). Cada isoenzima é predominantemente encontrada em um tecido humano específico: A CK-BB é a encontrada em maior quantidade no cérebro, a CK-MM nos músculos esqueléticos e miocárdio, e a CK-MB é específica do miocárdio (LIMA et al., 1992; LO et al., 2010). A distribuição relativa das isoenzimas em alguns dos órgãos mostra que o músculo possui 96\% de CK-MM e apenas 4\% de CK-MB, o cérebro e o pulmão apresentam 90\% de CKBB e $10 \%$ de CK-MM, o coração apresenta 60\% de CK-MM e 40\% de CK-MB (MOURA et al., 1982; MOURA et al., 2008; NOGUEIRA et al., 1990).

Existem ao menos cinco isoformas conhecidas de CK (PEREIRA; JUNIOR, 2007; PESCE; KAPLAN, 1990), das quais três localizam-se no citoplasma (CK-MM, CK-MB e CK-BB) e outras duas (CK-Mi ubíqua e CK-Mi sarcomérica ou CK- $\mathrm{Mi}_{\mathrm{a}}$ e CK-Mib respectivamente) na mitocôndria (BRANCACCIO et al., 2008; PEREIRA; JUNIOR, 2007; PILLA, 2003). A CK-MM tanto pode ser um marcador de doenças musculares quanto pode ser encontrada em diversas áreas das miofibrilas, onde há um alto consumo de ATP (BRANCACCIO et al., 2008; MAUGHAN; GLEESON; GREENHAFF, 2000). A CK-MM é ligada especificamente à estrutura da linha $\mathrm{M}$ da fibra muscular, que está localizada no sarcômero (BRANCACCIO et al., 2008; BRANCACCIO; MAFFULLI; LIMONGELLI, 2007). A CK-MB aumenta com o infarto agudo do miocárdio, e a CK-BB aumenta com danos cerebrais (BRANCACCIO et al., 2008).

A creatina quinase sérica (isoenzima CK-MM) é um marcador bioquímico que caracteriza a ruptura da membrana celular (BOUCHARD; HOFFMAN, 2011) e é utilizada frequentemente como marcador de dano muscular (FOSCHINI et al., 2007; HENRY, 1995; MOUGIOS, 2007; WILMORE; COSTILL, 2001), determinando o estado funcional do tecido muscular (BRANCACCIO et al., 2008). Sua determinação é de grande valia na investigação de lesões musculoesqueléticas (MOURA et al., 1982).

Tanto o treinamento excêntrico quanto o treinamento de resistência para pessoas que não possuem este hábito podem causar dor muscular, o que irá causar uma diminuição temporária das funções musculares e um aumento do extravazamento de proteínas intracelulares (ABOODARDA et al., 2011; NETO et al., 2007; STEVENS, 1996). Esta situação de dor muscular tardia é particularmente evidente após realização de exercícios excêntricos, manifestando-se, em média, 24 a $48 \mathrm{~h}$ após o término do exercício (SBRICCOLI et al., 2001).

Atividade intensa ou qualquer lesão no músculo esquelético ou cardíaco elevam os níveis séricos de creatina quinase (BURTIS; ASHWOOD; BRUNS, 2008; FRÉJAVILLE; KAUMOUN, 1989; MOURA et al., 1982; PESCE; KAPLAN, 1990). O dano muscular é uma consequência sistêmica da atividade física (LAC; MASO, 2004) e está associado à liberação de enzimas musculares (no caso, a creatina quinase) (REILLY et al., 2005; TOTSUKA et al., 2002). Sua atividade no plasma varia conforme as condições 
fisiológicas, tais como alterações musculares causadas tanto por atividades físicas de alta intensidade ou devido a certos tipos de patologias (por exemplo: infarto do miocárdio, rabdomiólise ou distrofia muscular progressiva) (BRANCACCIO et al., 2008; GARCIA, 2004). Há, portanto, uma sensibilidade da atividade da creatina quinase às lesões musculares (LÓPEZ, 1969), sugerindo que o nível de concentração plasmática de creatina quinase pode ser considerado um indicador de lesão muscular (ABOODARDA et al., 2011). Esta concentração aumenta como consequência de treinamento intenso e prolongado (BRANCACCIO et al., 2008; BRANCACCIO et al., 2007), sugerindo uma deterioração progressiva na estrutura da membrana muscular.

A resposta da liberação da creatina quinase ao exercício depende tanto de características individuais (TOTSUKA et al., 2002) quanto do protocolo de exercícios e do estado de treinamento do indivíduo (MACHADO et al., 2009). Os valores apresentados por indivíduos do sexo masculino são maiores que os homólogos do sexo feminino (MOURA et al., 1982; PESCE; KAPLAN, 1990). Existem diferenças relacionadas com idade, sexo e raça para a atividade sérica de CK. A massa muscular e a atividade física também parecem influenciar nesta atividade (BRANCACCIO et al., 2007; PESCE; KAPLAN, 1990). Percebe-se, portanto, uma grande variação interindividual (LAZARIM et al., 2009).

Apesar de não avaliar a fração MM da creatina quinase, Black, Quallich et al. (BLACK; QUALLICH; GARELECK, 1986) encontraram uma maior concentração média de CK total em pessoas negras que em pessoas brancas (BLACK et al., 1986), sugerindo que há uma diferença racial na concentração da creatina quinase. Johnston, Lloyd et al. (JOHNSTON et al., 1996) encontraram resultado similar em sua pesquisa (JOHNSTON et al., 1996).

Existe uma grande variabilidade individual no momento que se atinge o valor de pico de atividade de CK após o exercício. A CK tende a alcançar um máximo entre 16 e $24 \mathrm{~h}$ depois da atividade física e permanece elevada por aproximadamente $72 \mathrm{~h}$ (PESCE; KAPLAN, 1990). O estudo feito por Aboodarda et al., demonstrou uma tendência de aumento de $\mathrm{CK}$ a partir das $24 \mathrm{~h}$ e o valor de pico de atividade da mesma foi atingido no terceiro dia após o exercício e manteve-se elevada até o quinto dia (ABOODARDA et al., 2011). Totsuka, Nakaji et al., encontraram concentração de pico de CK variando entre 184 $\pm 16 \mathrm{IU} / 1$ e $751 \pm 81 \mathrm{IU} / 1$ entre os 15 indivíduos estudados (TOTSUKA et al., 2002). Ispirlidis et al. encontraram um aumento de CK logo após a partida de futebol, e atingiu seu pico 48 h após o término do jogo (ISPIRLIDIS et al., 2008).

\section{Lactato desidrogenase (LDH)}

A oxidação do lactato a piruvato é uma reação reversível catalisada pela lactato desidrogenase, que é uma enzima de transferência de hidrogênio, (BURTIS et al., 2008) encontrada no citoplasma de todas as células e tecidos (HENRY, 2008). A LDH está envolvida no metabolismo muscular (BRANCACCIO; LIMONGELLI; MAFFULLI, 2006) e é abundante no músculo esquelético, fígado, miocárdio, eritrócitos e rim (MOTTA, 2009). É uma enzima catalizadora que, em condições de anaerobiose, atua na redução do piruvato a lactato, em uma reação reversível (FETT et al., 2004; FRANÇA et al., 2006; MAUGHAN et al., 2000). Em indivíduos adultos, os valores de LDH não sofrem alteração com a idade ou sexo (HENRY, 2008). 
Vários estudos utilizam a LDH como marcador de lesão muscular (ISPIRLIDIS et al., 2008; MENA; MAYNAR; CAMPILLO, 1996; SINGH et al., 2011; VAN DE VYVER; MYBURGH, 2012). Normalmente, enzimas como a LDH são citoplasmáticas, estando limitadas no interior das células, apresentando uma baixa concentração sérica (CRUZAT et al., 2007; MOTTA, 2009). A tensão mecânica imposta às fibras musculares durante os exercícios irá causar um aumento da permeabilidade do sarcolema, levando a LDH a evadir-se para a corrente sanguínea, por isso, o aumento da concentração destas no sangue, sugere que houve algum tipo de lesão nas células (CRUZAT et al., 2007; FOSCHINI et al., 2007; KNIFIS et al., 2008; VAN DE VYVER; MYBURGH, 2012; WILMORE; COSTILL, 2001). A LDH é utilizada como um dos marcadores conhecidos de lesão muscular durante a atividade física e exercícios (FOSCHINI et al., 2007; HAMMOUDA et al., 2012; LAZARIM et al., 2009). A atividade física exerce apenas um pequeno efeito sobre a LDH (HENRY, 2008). Tanada, citado por Henry, afirma que até mesmo a atividade física extenuante ocasiona um aumento de somente $25 \%$ nos valores médios (HENRY, 2008).

Existem várias frações isoenzimáticas, todas são tetrâmeros, e são formadas por subunidades $\mathrm{H}$ para a cadeia polipeptídica cardíaca e $\mathrm{M}$ para a cadeia polipeptídica muscular esquelética (MOTTA, 2009; PEREIRA; JUNIOR, 2007). A LDH compõe-se de 5 frações e as isoenzimas encontradas são: LDH-1 (HHHH), LDH-2 (HHHM), LDH-3 (HHMM), LDH-4 (HMMM), LDH-5 (MMMM) (BRANCACCIO et al., 2006; MOTTA, 2009; MOURA et al., 2008). No músculo esquelético e no fígado, há a predominância da isoenzima LDH-5 (MOURA et al., 2008). Esta isoenzima tem sua concentração elevada, devido, entre outros fatores, a traumas musculares e exercícios de alta intensidade (MOTTA, 2009; PEREIRA; JUNIOR, 2007). A distribuição relativa das isoenzimas da $\mathrm{LDH}$ em alguns dos órgãos mostra que coração apresenta $40 \%$ de $\mathrm{LDH}_{1}, 35 \%$ de $\mathrm{LDH}_{2}$, $20 \%$ de $\mathrm{LDH}_{3}, 5 \%$ de $\mathrm{LDH}_{4}$ e $0 \%$ de $\mathrm{LDH}_{5}$, o músculo apresenta $60 \%$ de $\mathrm{LDH}_{5}, 30 \%$ de $\mathrm{LDH}_{4}$ e $10 \%$ de LDH3 (MOURA et al., 2008).

O teste de LDH, quando combinado com aumentos de $\mathrm{CK}$, e maiores elevações de aspartato aminotransferase (AST) que em alanina aminotransferase (ALT), mostram indício de lesão muscular ou cardíaca (HENRY, 2008).

\section{Aspartato aminotransferase (AST) ou transaminase glutâmica oxalacética (TGO)}

A AST é uma enzima catalisadora que atua na transferência de grupos amina e cetona entre alfa-aminoácidos e alfa-cetoácidos sendo por esta razão uma transferase (NOGUEIRA et al., 1990). As aminotransferases são vastamente distribuídas nos diversos tecidos humanos, com atividades mais elevadas de AST-TGO no músculo esquelético, fígado e miocárdio (BURTIS et al., 2008; HENRY, 2008; MOTTA, 2009). A AST-TGO é uma das enzimas catalizadoras que exercem um papel central na síntese e degradação dos aminoácidos, também atuando como ponte entre o metabolismo do aminoácido e do carboidrato (MOTTA, 2009).

Existem duas frações enzimáticas, uma citoplasmática (correspondendo a uma fração de 60\%) e outra mitocondrial (correspondendo a uma fração de 40\%) (BURTIS et al., 2008; NOGUEIRA et al., 1990). Esta proteína também é utilizada como marcador de dano muscular induzido pelo exercício (HAMMOUDA et al., 2012; LAZARIM et al., 2009). Normalmente, esta proteína é incapaz de atravessar a membrana celular e um incremento das concentrações desta na circulação, reflete alteração na permeabilidade e estrutura da 
membrana miofibrilar, indicando indiretamente que houve lesão muscular (CRUZAT et al., 2007; KNIFIS et al., 2008).

Nos homens, o principal determinante dos valores de AST-TGO é a atividade física: os exercícios extenuantes (treinamento intensivo) ocasionam um aumento de até três vezes o valor de repouso (HENRY, 2008). Alguns estudos vêm sendo feitos valendo-se da ASTTGO como marcador de lesão muscular (DUFFIELD; CANNON; KING, 2010; LIPPI et al., 2012; MENA et al., 1996; WASKIEWICZ et al., 2012). A variação diária dos valores de AST-TGO está em torno de 5 a 10\% (HENRY, 2008).

\section{Alanina aminotransferase (ALT) ou transaminase glutamato-piruvato (TGP)}

A ALT-TGP catalisa a reação reversível para a produção de alanina a partir do piruvato (BURTIS; ASHWOOD; ALDRICH, 1998; SMITH; MARKS; LIEBERMAN, 2007). Esta enzima está presente no fígado, músculo esquelético e no coração (BURTIS et al., 1998). Esta enzima é exclusivamente citoplasmática (NOGUEIRA et al., 1990).

A atividade física extenuante em pessoas do sexo masculino ocasiona um aumento nos valores de ALT-TGP em até 50\% (HENRY, 2008). Há uma variação diária de AST-TGP de 10 a 30\% (HENRY, 2008).

\section{Mioglobina}

A mioglobina é um composto protéico que contém ferro e que armazena o oxigênio intramuscular, participando de forma funcional de sua difusão da membrana celular para as mitocôndrias contidas no interior da célula muscular (FOSS, 2010; MCARDLE; KATCH; KATCH, 2003). Danos nos componentes contráteis do tecido muscular ou micro lacerações liberam mioglobina, elevando seu nível sérico (MCARDLE et al., 2003).

\section{Troponina I}

A troponina possui três subunidades: troponina I (que se une à actina), troponina $\mathrm{T}$ (que se une à tropomiosina) e a troponina $\mathrm{C}$ (que pode se unir aos íons de cálcio) (MAUGHAN et al., 2000). A troponina I é um biomarcador específico de danos em fibras musculares (MCARDLE et al., 2003).

\section{CONCLUSÃO}

O presente estudo teve por objetivo descrever os principais métodos de apoio ao diagnóstico de lesões musculares. Pode-se observar que os exames de ultrassonografia, tomografia computadorizada, ressonância nuclear magnética, termografia, creatina quinase, lactato desidrogenase, aspartato aminotransferase, miosina, troponina I, e interleucina podem apoiar o diagnóstico de lesão muscular em maior ou menor grau, de acordo com cada situação específica. $\mathrm{O}$ conhecimento dos métodos descritos instrumentaliza a decisão dos profissionais de saúde no sentido da solicitação ou indicação do método de apoio ao diagnóstico mais apropriado para cada situação com que se defrontam na prática clínica. 


\section{REFERÊNCIAS BIBLIOGRÁFICAS}

1. ABOODARDA, S. J. et al. Muscle strength and damage following two modes of variable resistance training. J Sports Sci Med, v. 10, n. 4, p. 635-42, 2011.

2. ALVES, L. M.; SOARES, R. P.; LIEBANO, R. E. Incidência de lesões na prática do rúgbi amador no Brasil. Fisioterapia e Pesquisa, v. 15, n. 2, p. 131-135, 2008.

3. BANDEIRA, F. et al. Pode a termografia auxiliar no diagnóstico de lesões musculares em atletas de futebol? Revista Brasileira de Medicina do Esporte, v. 18, n. 4, p. 246$251,2012$.

4. BAUDUER, F. et al. Déséquilibres biochimiques, déshydratation, récupération et rugby professionnel - données du suivi longitudinal de la Ligue nationale de rugby et de l'exploration par bioimpédance multifréquence. Science \& Sports, v. 26, n. 1, p. 19-24, 2011.

5. BERZ, R.; SAUER, H. The medical use of Infrared-Thermography; History and recent applications. Deutsche Gesellschaft für Zerstörungsfreie Prüfung eV (Ed): Thermografie-Kolloquium, 2007.

6. BLACK, H. R.; QUALLICH, H.; GARELECK, C. B. Racial differences in serum creatine kinase levels. Am J Med, v. 81, n. 3, p. 479-87, Sep 1986.

7. BONTRAGER, K. L. Tratado de técnica radiológica e base anatômica. $5^{\mathrm{a}}$ edição. Rio de Janeiro: Guanabara Koogan, 2003.

8. BONTRAGER, K. L.; LAMPIGNANO, J. P. Tratado de posicionamento radiográfico e anatomia associada. $7^{\mathrm{a}}$ Edição. Rio de Janeiro: Elsevier, 2010.

9. BOUCHARD, C.; HOFFMAN, E. P. Genetic and molecular aspects of sport performance Oxford: Blackwell Publishing, 2011.

10. BRANCACCIO, P.; LIMONGELLI, F. M.; MAFFULLI, N. Monitoring of serum enzymes in sport. Br J Sports Med, v. 40, n. 2, p. 96-7, Feb 2006.

11. BRANCACCIO, P. et al. Serum enzyme monitoring in sports medicine. Clin Sports Med, v. 27, n. 1, p. 1-18, vii, Jan 2008.

12. BRANCACCIO, P.; MAFFULLI, N.; LIMONGELLI, F. M. Creatine kinase monitoring in sport medicine. Br Med Bull, v. 81-82, n. 1, p. 209-30, January 1, 2007 2007.

13. BRANT, W. E.; HELMS, C. A. Fundamentos de radiologia: diagnóstico por imagem. $3^{\text {a }}$ edição. Rio de Janeiro: Guanabara Koogan, 2008.

14. BRIOSCHI, M. L. et al. Documentação da síndrome dolorosa miofascial por imagem infravermelha. Acta Fisiátrica, v. 14, n. 1, p. 41-48, 2007.

15. BRIOSCHI, M. L. et al. Utilização da imagem infravermelha em reumatologia. Revista Brasileira de Reumatologia, v. 47, p. 42-51, 2007. 
16. BRIOSCHI, M. L.; YENG, L. T.; TEIXEIRA, M. J. Diagnóstico avançado em dor por imagem infravermelha e outras aplicações. Prática Hospitalar, p. 93-8, 2007.

17. BURTIS, C. A.; ASHWOOD, E. R.; ALDRICH, J. E. Tietz Fundamentos de química clínica. Rio de Janeiro: Guanabara Koogan, 1998.

18. BURTIS, C. A.; ASHWOOD, E. R.; BRUNS, D. E. Tietz, Fundamentos de química clínica. $6^{\text {a }}$ Edição. Rio de Janeiro: Elsevier, 2008.

19. CAMPBELL, M. K. Bioquímica. Porto Alegre: Artmed, 2000.

20. CARVALHO, A. R. D. et al. Variação de temperatura do músculo quadríceps femoral exposto a duas modalidades de crioterapia por meio de termografia. Revista Brasileira de Medicina do Esporte, v. 18, p. 109-111, 2012.

21. CRUZAT, V. F. et al. Aspectos atuais sobre estresse oxidativo, exercícios físicos e suplementação. Revista Brasileira de Medicina do Esporte, v. 13, p. 336-342, 2007.

22. CUNNIFFE, B. et al. Time course of changes in immuneoendocrine markers following an international rugby game. Eur J Appl Physiol, v. 108, n. 1, p. 113-22, Jan 2010.

23. DOYON, D. et al. Diagnóstico por imagem em ressonância magnética. Rio de Janeiro: Medsi, 2000.

24. DUFFIELD, R.; CANNON, J.; KING, M. The effects of compression garments on recovery of muscle performance following high-intensity sprint and plyometric exercise. J Sci Med Sport, v. 13, n. 1, p. 136-40, Jan 2010.

25. DUFFIELD, R. et al. Post-match changes in neuromuscular function and the relationship to match demands in amateur rugby league matches. J Sci Med Sport, v. 15, n. 3, p. 238-43, May 2012.

26. ESTON, R.; BYRNE, C.; TWIST, C. Muscle function after exercise-induced muscle damage: Considerations for athletic performance in children and adults. Journal of Exercise Science and Fitness, v. 1, n. 2, p. 85-96, 2003.

27. FERNANDES, T. L.; PEDRINELLI, A.; HERNANDEZ, A. J. Lesão muscular fisiopatologia, diagnóstico, Tratamento e apresentação clínica. Revista Brasileira de Ortopedia, v. 46, n. 3, p. 247-55, 2011.

28. FETT, C. A. et al. A suplementação de ácidos graxos ômega 3 e triglicérides de cadeia média não alteram os indicadores metabólicos em um teste de exaustão. Revista Brasileira de Medicina do Esporte, v. 10, p. 44-49, 2004.

29. FOSCHINI, D.; PRESTES, J.; CHARRO, M. A. Relação entre exercício físico, dano muscular e dor muscular de início tardio. Revista Brasileira de Cineantropometria \& Desempenho Humano, v. 9, n. 1, p. 101-6, 2007. 
30. FOSS, M. L. Fox, bases fisiológicas do exercício e do esporte. Rio de Janeiro: Guanabara Koogan, 2010.

31. FRANÇA, S. C. A. et al. Resposta divergente da testosterona e do cortisol séricos em atletas masculinos após uma corrida de maratona. Arquivos Brasileiros de Endocrinologia \& Metabologia, v. 50, p. 1082-1087, 2006.

32. FRÉJAVILle, J. P.; KAUMOUN, P. Manual de exames de laboratório: 500 exames. Indicação, técnica, interpretação e diagnóstico. Rio de Janeiro: Livraria Atheneu, 1989.

33. GABBETT, T. J. Incidence of injury in semi-professional rugby league players. Br $\mathbf{J}$ Sports Med, v. 37, n. 1, p. 36-43; discussion 43-4, 2003.

34. GARCIA, M. C. Concentração plasmática de hormônios indicadores de overtraining em jogadores de futebol. 2004. (Mestrado). Instituto de Biologia, Universidade estadual de Campinas, Campinas.

35. GARRETT JR., W. E.; KIRKENDALL, D. T. A ciência do exercício e dos esportes. Porto Alegre: Artmed, 2003.

36. HAMMOUDA, $\mathrm{O}$. et al. Morning-to-evening difference of biomarkers of muscle injury and antioxidant status in young trained soccer players. Biological Rhythm Research, v. 43, n. 4, p. 431-438, 2012.

37. HENRY, J. B. Diagnósticos clínicos e tratamento por métodos laboratoriais. São Paulo: Manole, 1995.

38. Diagnósticos clínicos e tratamento por métodos laboratoriais. $20^{\mathrm{a}}$ Edição. Barueri: Manole, 2008.

39. HILDEBRANDT, C. et al. The Application of Medical Infrared Thermography in Sports Medicine In: ZASLAV, K. R. (Ed.). International Perspective on Topics in Sports Medicine and Sports Injury, 2012.

40. ISPIRLIDIS, I. et al. Time-course of changes in inflammatory and performance responses following a soccer game. Clin J Sport Med, v. 18, n. 5, p. 423-31, Sep 2008.

41. ITAKURA, D. A. Alterações térmicas na região sacral com diferentes colchões utilizados na prevenção de úlceras por pressão. 2012. (Mestrado). Tecnologia em Saúde, Pontifícia Universidade Católica do Paraná Curitiba.

42. JARVINEN, T. A. et al. Muscle injuries: optimising recovery. Best Pract Res Clin Rheumatol, v. 21, n. 2, p. 317-31, Apr 2007.

43. JOHNSTON, J. D. et al. Racial variation in serum creatine kinase levels. J R Soc Med, v. 89, n. 8, p. 462-4, Aug 1996.

44. JONES, B. F.; PLASSMANN, P. Digital infrared thermal imaging of human skin. IEEE Eng Med Biol Mag, v. 21, n. 6, p. 41-8, Nov-Dec 2002. 
45. JOUGLA, A.; MICALLEF, J. P.; MOTTET, D. Effects of active vs. passive recovery on repeated rugby-specific exercises. J Sci Med Sport, v. 13, n. 3, p. 350-5, May 2010.

46. KNIFIS, F. et al. Características antropométricas e sua relação com microlesões induzidas pelo exercício. Brazilian Journal of Biomotricity, v. 2, p. 122-31, 2008.

47. LAC, G.; MASO, F. Biological markers for the follow-up of athletes throughout the training season. Pathologie Biologie, v. 52, n. 1, p. 43-49, 2004.

48. LAHIRI, B. B. et al. Medical applications of infrared thermography: A review. Infrared Physics \& Technology, v. 55, n. 4, p. 221-235, 2012.

49. LAZARIM, F. L. et al. The upper values of plasma creatine kinase of professional soccer players during the Brazilian National Championship. J Sci Med Sport, v. 12, n. 1, p. 85-90, Jan 2009.

50. LIMA, A. O. et al. Métodos de laboratório aplicados à clínica: Técnica e interpretação. $7^{a}$ edição. Rio de Janeiro: Guanabara Koogan, 1992.

51. LIPPI, G. et al. Foot-strike haemolysis after a 60-km ultramarathon. Blood Transfus, v. 10, n. 3, p. 377-83, 2012.

52. LO, K. R. et al. Development and validation of a sensitive immunoassay for the skeletal muscle isoform of creatine kinase. J Sci Med Sport, v. 13, n. 1, p. 117-9, 2010.

53. LOPES, A. S. et al. Estudo clínico e classificação das lesões musculares. Rev Bras Ortop, v. 28, n. 10, p. 707-17, 1993.

54. LÓPEZ, J. C. Enzimología: Química de las enzimas. Métodos de preparación y valoración. Nomenclatura, classificación y descripción. Aplicación en medicina. Barcelona: Editorial científico-médica, 1969.

55. LUFKIN, R. B. Manual de ressonância magnética. $2^{a}$ edição. Rio de Janeiro: Guanabara Koogan, 1999.

56. MACHADO, M. et al. Effect of a Single Dose of Caffeine Supplementation and Intermittent-interval Exercise on Muscle Damage Markers in Soccer Players. Journal of Exercise Science and Fitness, v. 7, n. 2, p. 91-97, 2009.

57. MAUGHAN, R.; GLEESON, M.; GREENHAFF, P. L. Bioquímica do exercício e treinamento. Barueri: Manole, 2000.

58. MCARDLE, W. D.; KATCH, F. I.; KATCH, V. L. Fisiologia do Exercício: Energia, Nutrição e Desempenho Humano. $5^{\text {a }}$ Edição. Rio de Janeiro: Guanabara Koogan, 2003.

59. MENA, P.; MAYNAR, M.; CAMPILLO, J. E. Changes in plasma enzyme activities in professional racing cyclists. Br J Sports Med, v. 30, n. 2, p. 122-4, 1996. 
60. MITTELSTAEDT, C. A. Ultra-sonografia Geral. Rio de Janeiro: Livraria e editora REVINTER, 2000.

61. MOTTA, V. T. Bioquímica Clínica: princípios e interpretações. $5^{\mathrm{a}}$ ed. Medbook, 2009.

62. MOUGIOS, V. Reference intervals for serum creatine kinase in athletes. Br J Sports Med, v. 41, n. 10, p. 674-8, 2007.

63. MOURA, R. D. A. et al. Técnicas de laboratório. $2^{\text {a }}$ edição. Rio de Janeiro Livraria Atheneu, 1982.

64. MOURA, R. D. A. et al. Técnicas de laboratório. $3^{\text {a }}$ edição. São Paulo: Editora Atheneu, 2008.

65. NETO, J. M. F. A. et al. Manutenção de microlesões celulares e respostas adaptativas a longo prazo no treinamento de força. Brazilian Journal of Biomotricity, v. 1, p. 87$102,2007$.

66. NOGUEIRA, D. M. et al. Métodos de bioquímica clínica. São Paulo: Pancast, 1990.

67. PEREIRA, B.; JUNIOR, T. P. D. S. Metabolismo celular e exercício físico: aspectos bioquímicos e nutricionais. $2^{a}$ edição. São Paulo: Phorte, 2007.

68. PESCE, A. J.; KAPLAN, L. A. Química clínica: métodos. Buenos Aires: Editorial Médica Panamericana, 1990.

69. PETERSON, L.; RENSTRÖM, P. Lesões do esporte - prevenção e tratamento. São Paulo: Manole, 2002.

70. PILLA, C. Efeito dos aminoácidos de cadeia ramificada e seus cetoácidos sobre a atividade da creatinaquinase de cérebros de ratos jovens. 2003. (Doutor). Ciências básicas da saúde, Uiversidade Federal do Rio Grande do Sul, Porto Alegre.

71. PRANDO, A.; MOREIRA, F. A. Fundamentos de radiologia e diagnóstico por imagem. Rio de Janeiro: Elsevier, 2007.

72. REILLY, T. et al. Physiology of sports. Taylor \& Francis e-Library, 2005.

73. SARGENTIM, S. Treinamento de força no futebol. São Paulo: Phorte editora, 2010.

74. SBRICCOLI, P. et al. Exercise induced muscle damage and recovery assessed by means of linear and non-linear sEMG analysis and ultrasonography. J Electromyogr Kinesiol, v. 11, n. 2, p. 73-83, Apr 2001.

75. SCHAAP, M. et al. Fast noise reduction in computed tomography for improved 3-D visualization. IEEE Trans Med Imaging, v. 27, n. 8, p. 1120-9, Aug 2008. 
76. SINGH, T. K. et al. A comparison of muscle damage, soreness and performance following a simulated contact and non-contact team sport activity circuit. J Sci Med Sport, v. 14, n. 5, p. 441-6, Sep 2011.

77. SMITH, C.; MARKS, A. D.; LIEBERMAN, M. Bioquímica médica de Marks. $2^{\mathrm{a}}$ Edição. Porto Alegre: Artmed, 2007.

78. STEVENS, E. D. Effect of phase of stimulation on acute damage caused by eccentric contractions in mouse soleus muscle. J Appl Physiol (1985), v. 80, n. 6, p. 1958-62, Jun 1996.

79. STIMAC, G. K. Introdução ao diagnóstico por imagens. Rio de Janeiro: Guanabara Koogan, 1994.

80. STOLEN, T. et al. Physiology of soccer: an update. Sports Med, v. 35, n. 6, p. 501$36,2005$.

81. SUTTON, D. Radiologia e diagnóstico por imagem para estudantes de medicina. $6^{\text {a }}$ edição. São Paulo: Editora Roca, 1996.

82. TAN, J.-H. et al. Infrared thermography on ocular surface temperature: A review. Infrared Physics \& Technology, v. 52, n. 4, p. 97-108, 2009.

83. TOTSUKA, M. et al. Break point of serum creatine kinase release after endurance exercise. J Appl Physiol (1985), v. 93, n. 4, p. 1280-6, Oct 2002.

84. VAN DE VYVER, M.; MYBURGH, K. H. Cytokine and satellite cell responses to muscle damage: interpretation and possible confounding factors in human studies. $\mathbf{J}$ Muscle Res Cell Motil, v. 33, n. 3-4, p. 177-85, Aug 2012.

85. WASKIEWICZ, Z. et al. Acute metabolic responses to a 24-h ultra-marathon race in male amateur runners. Eur J Appl Physiol, v. 112, n. 5, p. 1679-88, May 2012.

86. WEBB, S. The physics of medical imaging. Philadelphia: Institute of Physics Publishing, 1988.

87. WESTBROOK, C.; KAUT, C. Ressonância magnética prática. Rio de Janeiro: Guanabara Koogan, 2000.

88. WILMORE, J. H.; COSTILl, D. L. Fisiologia do Esporte e do Exercício. São Paulo: Manole, 2001.

89. YENG, L. T.; KAZIYAMA, H. H. S.; TEIXEIRA, M. J. Síndrome dolorosa miofascial. Jornal brasileiro de oclusão, ATM e dor orofacial, v. 3, n. 9, p. 27-43, 2003. 